\title{
Emerging Function of Cardiac Macrophages Ushers in a New Era for the Electrophysiology of the Heart
}

\author{
Junichi Sugita, MD, PhD; Katsuhito Fujiu, MD, PhD
}

\begin{abstract}
Maintaining a coordinated heart rhythm is essential for maintaining the heart's pumping function and blood circulation. Every heartbeat is generated by electrical impulse propagation that is passing through gap junctions, which are composed of connexin proteins. In mammalian hearts, $\mathrm{C} \times 43, \mathrm{C} \times 40, \mathrm{C} \times 45$, and $\mathrm{C} \times 30.2$ are expressed and regulated by post-translational modification. Cardiac macrophages account for only a small number of total heart cells, but they reside all around the heart. They are primarily established prenatally, and they arise from embryonic yolk sac progenitors. Recently, increasing attention has been directed toward novel roles for cardiac resident macrophages, especially in the heart's electrical impulse conduction. Here, we provide an overview of the recent findings on connexins, with a focus on the emerging function of cardiac macrophages, and we discuss the future directions of treatment for heart disease.
\end{abstract}

Key Words: Arrhythmia; Atrioventricular node; Connexin43

$\mathbf{H}$ eart failure is a chronic disease and accounts for substantial morbidity and mortality worldwide. ${ }^{1}$ Its prevalence is increasing because of population aging and improved treatment for acute cardiovascular events that lead to sudden death. ${ }^{2}$ The prevalence of heart failure is estimated to be $1-3 \%$ in the adult population at large, and 5-9\% selectively in those aged $\geq 65$ years; $;, 4$ the prevalence in the USA is projected to increase by $25 \%$ in the general population in the next 20 years. ${ }^{5}$

Heart failure with preserved ejection fraction (HFpEF) is a heterogeneous disorder that lacks complete understanding, despite the increasing prevalence and attendant clinical and economic burdens. Clinical experience suggests that heart failure death in HFpEF is not classic pump failure, which is the case in heart failure with reduced ejection fraction (HFrEF). Rather, in many cases, it involves progressive pulmonary hypertension, right ventricular failure, and/or renal venous congestion and worsening renal function with ensuing multi-organ dysfunction. Increasing attention has recently been directed toward the role of the right ventricle because its dysfunction is common in HFpEF and is associated with mortality in heart failure patients. ${ }^{6,7}$

Regarding the cause of death, worsening heart failure accounts for an approximately similar proportion, namely $20-30 \%$, of total cardiovascular deaths both in HFpEF and in HFrEF. Sudden death accounts for up to $25-30 \%$ of deaths in the HFpEF population, whereas it constitutes $35-40 \%$ of all mortality events in the HFrEF population. ${ }^{8}$

QRS duration and morphology should be considered important prognostic information because it is indicative of more advanced cardiac pathology. Abnormal QRS duration and its morphology frequently identify subjects with clinically undetected cardiac abnormalities and an increased risk of mortality. ${ }^{9,10}$ Post-myocardial infarction patients with prolonged QRS duration have a significantly increased risk of mortality, although data associating QRS prolongation specifically with sudden death are less supportive. In non-ischemic cardiomyopathy, there is no evidence that QRS duration carries prognostic significance for predicting mortality or sudden death because of limited observations. ${ }^{11}$ In patients with heart failure and low ejection fraction, however, a significantly prolonged QRS duration, especially with the presence of left bundle branch block, predicts a benefit from cardiac resynchronization therapy.

The heart's electrical conduction system is vital for maintaining normal heart rhythm and cardiac function. Electrical impulses are generated at the sinoatrial node, and they propagate sequentially to the atrioventricular (AV) node for subsequent transmission to the ventricles via specialized conduction pathways. The electrical signals are conveyed from cell to cell through gap junctions, which are non-selective membrane pores that allow molecules $<1,000 \mathrm{Da}$ to transit and thus provide electrical continuity between two cells. ${ }^{12,13}$ At the molecular level, gap junction hemichannels, which are called "connexons", are integral membrane channels that are composed of six connexin molecules. The connexons converge at intercalated discs in clusters of hundreds to thousands and bind end to end with connexon hemichannels of apposing cells to form dense arrays of gap junction plaques. The plaques function as continuous conduits, allowing intracellular ions and other small molecules to pass freely between ventricular cardiomyocytes.

Received October 3, 2019; accepted October 3, 2019; J-STAGE Advance Publication released online November 13, 2019

Department of Cardiovascular Medicine (J.S., K.F.), Department of Advanced Cardiology (K.F.), the University of Tokyo, Tokyo, Japan

Mailing addresses: Junichi Sugita, MD, PhD and Katsuhito Fujiu, MD, PhD, Department of Cardiovascular Medicine, the University of Tokyo, 7-3-1 Hongo, Bunkyo-ku, Tokyo 113-8655, Japan. E-mail: jsugita-tky@umin.ac.jp; fujiu-tky@umin.ac.jp

ISSN-2434-0790 All rights are reserved to the Japanese Circulation Society. For permissions, please e-mail: cr@j-circ.or.jp 


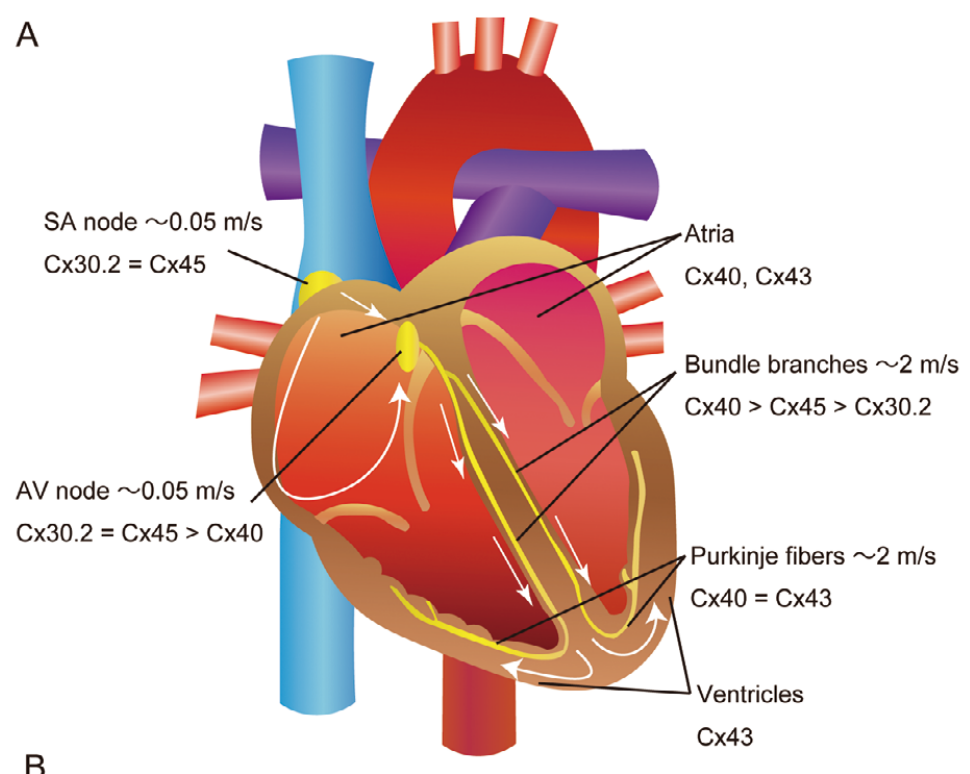

B
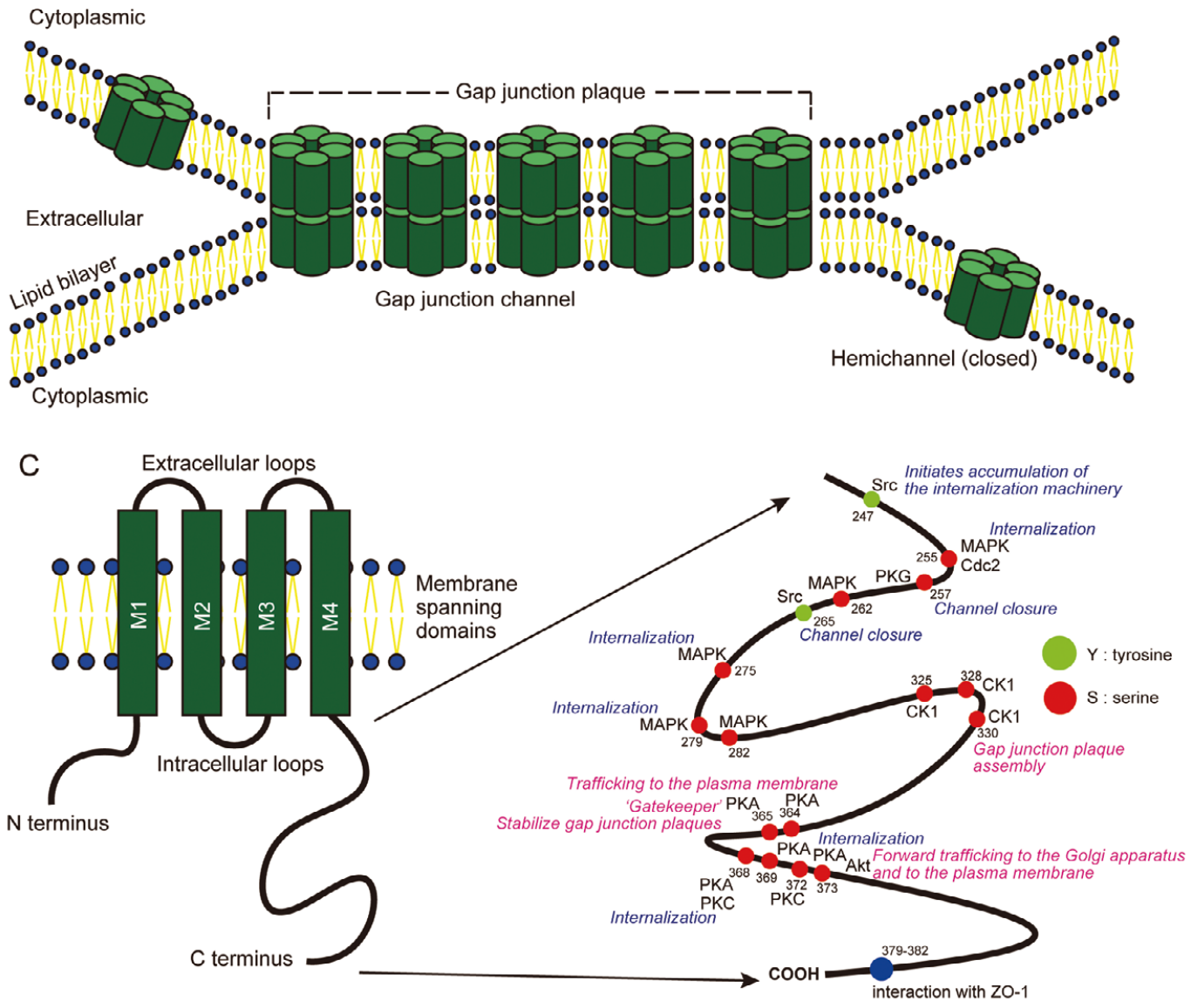

Figure 1. Cardiac connexins and their post-transcriptional modification. (A) Schematic diagram of the cardiac conduction system, showing the correlation between conduction velocity and connexin (Cx) expression. Note that connexin expression data are based on rodent experiments. ${ }^{21,24,33}$ (B) Schematic diagram of a gap junction plaque joining the cytoplasm of two adjacent cells. The opposed phospholipid bilayers are traversed by connexons that cluster and aggregate in the plane of the membrane to form a gap junction plaque. (C) Connexin protein subunits are tetra-spanning membrane proteins that share two extracellular loops. The subunits vary mainly in their cytoplasmic loop and carboxy-terminal regions. Connexin topology with phosphorylation sites and zonula occludens protein 1 (ZO-1) binding region. Green circles, tyrosine; red circles, serine. Pink font, increased gap junctional intercellular communication (GJIC); blue font, decreased GJIC. Cdc2, cyclin-dependent kinase 2; CK1, casein kinase 1; MAPK, mitogen-activated protein kinase; PKA, protein kinase A; PKC, protein kinase C; PKG, protein kinase G. 
Connexins are named according to their respective molecular weight. The structural differences between them lie in the cytoplasmic loop and the carboxyl-terminal region. Each connexin subunit contains four hydrophobic transmembrane domains, consisting of two extracellular loops, one cytoplasmic loop, and one cytoplasmic $\mathrm{N}$-terminal as well as a C-terminal region (Figure 1).

More than twenty isoforms of connexin have been recognized, ${ }^{14,15}$ and four of them contribute to the heart: $\mathrm{Cx} 43$, Cx40, Cx45, and Cx30.2. Different parts of the heart have varying requirements for the degree of electrical coupling that is needed. The large Purkinje myocytes are strongly coupled because the specialized ventricular conduction system needs to spread the activation wave rapidly over the ventricles. To create a delay between the atrial and ventricular contraction, a very low degree of coupling is required in the AV node. Similarly, to allow pacemaker function, pacemaker myocytes in the sinoatrial node need to be weakly coupled. Otherwise, the pacemaker would be silenced by the surrounding working myocardium. ${ }^{16,17}$

In cardiac myocytes, connexins are preferentially located at the intercalated disc. They contribute to the anisotropic nature of cardiac impulse conduction. ${ }^{18} \mathrm{Cx} 43$, which is the most abundant, has been found in almost all parts of the heart, except for the cells of the sinoatrial nodes. In contrast, $\mathrm{Cx} 40$ seems to be present specifically in the atrium and the ventricular conduction system. Cx45 is less abundant and is preferentially present in the conduction system. ${ }^{19-21} \mathrm{In}$ mice, $\mathrm{Cx} 30.2$ is expressed in the cardiac conduction system, predominantly in the sinoatrial node and the AV nodes. ${ }^{22}$ The human ortholog of $\mathrm{Cx} 30.2$, the Cx31.9 protein, however, is not detectable and is unlikely to contribute to either the impulse generation and conduction system or the working myocardium of the human heart. ${ }^{23}$ In cardiomyocytes, single-gap junction channel conductance ranges from 9 picosiemens $(\mathrm{pS})$ for $\mathrm{Cx} 30.2^{24}$ to approximately $20 \mathrm{pS}$ for $\mathrm{Cx} 45$ channels to $45-75 \mathrm{pS}$ for $\mathrm{Cx} 43$ channels and approximately $200 \mathrm{pS}$ for $\mathrm{Cx} 40$ channels. These conductance values depend on $\mathrm{pH},{ }^{25}$ on extracellular $\left[\mathrm{Ca}^{2+}\right],{ }^{26-28}$ on extracellular fatty acid composition, ${ }^{29,30}$ and on the phosphorylation state of the connexins. ${ }^{31}$

Cardiac $\mathrm{Cx} 43$ has a relatively short half-life, on the order of $1-5 \mathrm{~h}$, and $<2 \mathrm{~h}$ at the plasma membrane. ${ }^{32,33}$ This suggests that both the synthesis and the degradation of a gap junction are dynamic processes, and that regulation of protein stability may be a major mechanism of gap junction remodeling. Cx43 is translated in the rough endoplasmic reticulum (ER); it undergoes oligomerization in the postER/Golgi compartment, after which Cx43-containing vesicles are thought to be transported to the periphery of existing gap junctions at the plasma membrane. Undocked connexons aggregate into the gap junction in a zonula occuludens-1 (ZO-1)-dependent manner. ${ }^{34}$ Intracellular scaffolding proteins, such as ZO-1, anchor $\mathrm{Cx} 43$ via its c-terminus and regulate the gap junction's plaque size. Connexon internalization from the plasma membrane is also an important regulatory step in determining the level of gap junction coupling.

Normal gap junction communication is required for simultaneous initiation of action potentials of cardiomyocytes and an organized heart contraction. Alterations in gap junction coupling occur with many forms of heart disease. These coupling alterations lead to defects in electrical excitation that can result in malignant arrhythmias and sudden cardiac death.
Gap junctional intercellular communication (GJIC) is regulated by post-translational regulation of $\mathrm{Cx} 43$, either through direct control of channel activity or by modulating protein-protein interactions and Cx43 localization. Phosphorylation is by far the most well-studied modification, with several studies demonstrating its instrumental role upon regulation of channel gating, trafficking, assembly/ disassembly, and degradation of gap junction channels. ${ }^{35-37}$ At the C-terminus of $\mathrm{Cx} 43,21$ phosphorylation sites (19 serine residues and 2 tyrosine residues) that are regulated by the action of more than 10 kinases and phosphatases, including protein kinase $\mathrm{C}(\mathrm{PKC})$, protein kinase $\mathrm{A}$ (PKA), mitogen-activated protein kinases, Src kinases, and protein phosphatase $2 \mathrm{~A}$, have been described. ${ }^{38,39}$

The lifecycle of $\mathrm{Cx} 43$ is regulated in a well-balanced manner by specific phosphorylation and dephosphorylation. For example, phosphorylation at S364 and/or S365 regulates its trafficking to the plasma membrane, contributing to increased GJIC, whereas phosphorylation of S368 results in $\mathrm{Cx} 43$ internalization and the downregulation of GJIC. ${ }^{\mathbf{4 0 , 4 1}}$ Under pathological conditions, such as myocardial ischemia and wound healing, the phosphorylation of the residue $\mathrm{S} 373$, followed by simultaneous phosphorylation of S279, S282, and Y247, induces an acute increase in gap junction size, followed by rapid internalization of $\mathrm{Cx} 43$ and the downregulation of GJIC. ${ }^{34}$

Notably, myocardial ischemia constitutes a paradigmatic example of the dramatic alteration of the dynamics of Cx43 phosphorylation, which affects channel conductance and localization. During ischemia, the phosphorylation of $\mathrm{S} 325, \mathrm{~S} 328$, and/or S330, which are restricted to the intercalated disk, is lost. ${ }^{42}$ In addition, dephosphorylation of S365, which is called the GJIC gatekeeper, takes place, enabling subsequent phosphorylation of S368 by PKC, which negatively affects the electrical coupling between cardiomyocytes. ${ }^{43,44}$ Ischemia-induced phosphorylation of S373 also creates a so-called mode-1 binding domain for 14-3-3 proteins, which drives the internalization of $\mathrm{Cx} 43 .{ }^{45}$

Cx43 lateralization has been implicated in pathological cardiac conditions that are associated with a decrease in electrical coupling. The mechanisms that underlie Cx43's lateralization remain largely unknown. One possible explanation is that the activation of Src kinase and its interactions with $\mathrm{Cx} 43$ and ZO-1 may contribute to lateralization. ${ }^{\mathbf{4 6 , 4 7}}$ Src activation leads to the separation of Cx43 from ZO-1, and gap junction plaque moves away from the intercalated disks to the lateral membranes. Another possibility is related to the acetylation of $\mathrm{Cx} 43 .{ }^{48}$ Colussi et al found that $\mathrm{Cx} 43$ is lateralized, acetylated, and co-immunoprecipitated with the acetylase P300/CBP-associated factor in a model of Duchenne cardiomyopathy (spontaneous $D m d^{m d x}$ mutant mice). 48

Cx43 dephosphorylation is a characteristic of ischemia, arrhythmia, and of a failing/aging myocardium. ${ }^{49}$ When gap junctional coupling decreases, conduction becomes highly discontinuous, and a propensity toward reentrant arrhythmias increases. In addition, gap junctional uncoupling can increase the incidence of arrhythmic triggers and their propagation into an adjacent myocardium..$^{\mathbf{5 0}}$

Macrophages are a type of white blood cell that engulfs and digests infectious agents, cellular debris, and foreign substances. The canonical function of circulating and resident macrophages is to provide innate immune surveillance of individual organs. This paradigm, however, was questioned regarding the origin of macrophages. A sub- 


\section{A Innate immune funtion}

Canonical macrophage functions

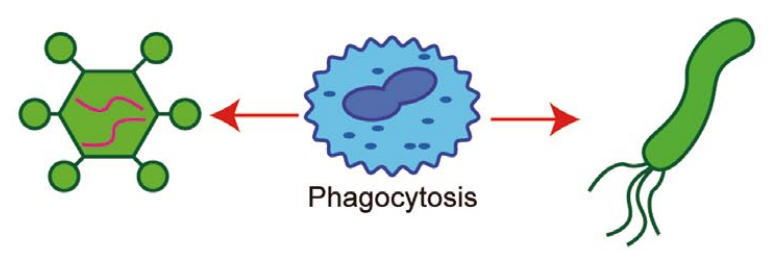

B Atrioventricular conduction in the steady state

Hulsmans et al., 2017

\section{Connexin-43-containing gap junctions}

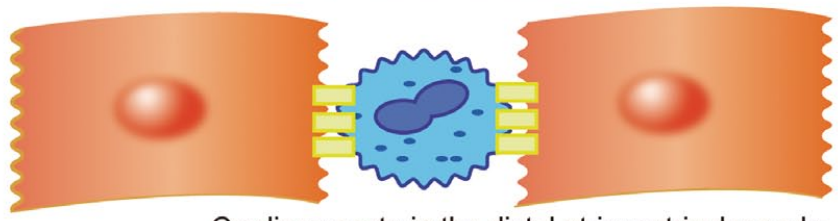

Cardiomyocyte in the distal atrioventricular node

\section{Arrhythmia susceptibility in diabetic state}

Monnerat et al., 2016

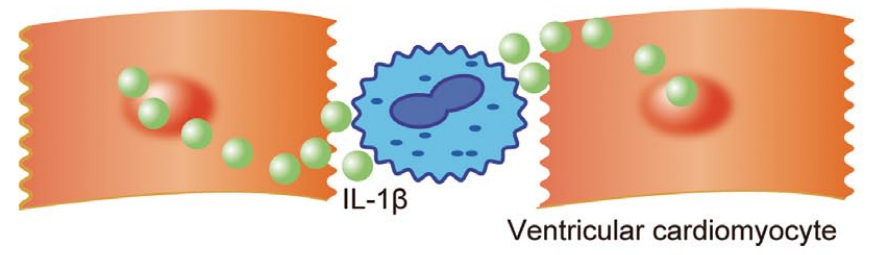

\section{Diastolic dysfunction in aging or hypertension}

Hulsmans et al., 2018

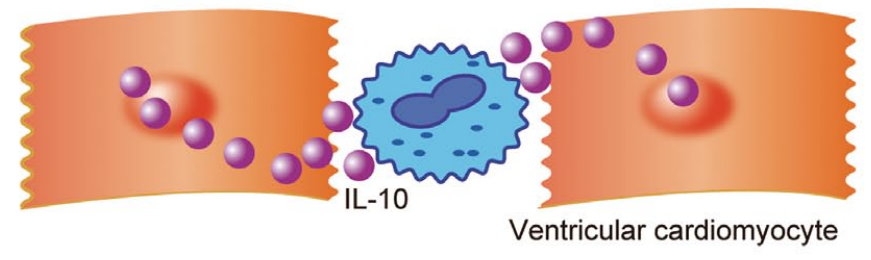

Figure 2. Contributions of cardiac macrophage to cardiac pulse conduction. (A) Macrophages were first described as phagocytic cells, which fight against viral or bacterial infections. (B) Emerging evidence, however, indicates that macrophages can influence the homeostasis of the heart. Macrophages that are present in the atrioventricular node actively participate in the establishment of cardiac rhythm, acting via connexin-43-containing gap junctions. In addition, macrophages play crucial roles in both aging and disease, such as diabetes and hypertension. Diabetes induces a sterile inflammation that activates toll-like receptor 2 (TLR2) and the NOD-like receptor protein 3 (NLRP3) inflammasome in macrophages to produce interleukin (IL)-1 $\beta$, which causes arrhythmia propensity. IL-10 that is produced by macrophages promotes diastolic dysfunction in both advanced age and hypertension. population of macrophages that originates from embryonic tissue does not come through the bloodstream; they reside and proliferate in virtually all body tissues, including the brain, spleen, liver, lung, bone marrow, kidney, pancreas, and peritoneum. They are seeded before birth, can maintain themselves in adults by self-renewal, ${ }^{\mathbf{5 1}}$ and can act specifically on each organ. For example, resident macrophages of adipose tissue contribute to the regulation of thermogenesis, ${ }^{52}$ of the spleen and liver for iron recycling,,${ }^{53}$ and of the brain to participate in the process of synaptic maturation. ${ }^{54}$ Such non-canonical roles emphasize the complex physiology of macrophages and their ability to perform specific tasks, depending on their microenvironment, in addition to their host defense ability. ${ }^{\mathbf{5 5}}$

Resident cardiac macrophages in mice account for approximately $5-10 \%$ of non-myocytes in the heart, and the vast majority originate from embryonic yolk sac and fetal liver progenitors. They appear spindle-shaped and are intercalated between cardiomyocytes, fibroblasts, and endothelial cells. ${ }^{56}$ Replenishment occurs at the rate of approximately once per month via proliferation. CCR2 ${ }^{+}$ macrophages are replenished by blood monocyte recruitment and local proliferation, whereas CCR2- macrophages are repopulated largely by local proliferation. ${ }^{57}$

Recently, our view of cardiac conduction has been refined due to revelations regarding cardiac macrophages (Figure 2). Hulsmans et al found that cardiac macrophages facilitate electrical conduction through the distal AV node. ${ }^{58} \mathrm{Cx} 43$ containing gap junctions connect macrophages with conducting cardiomyocytes in the distal AV node. This coupling leads to cyclical depolarization of macrophages and modulates the electrical activity of cardiomyocytes. 
Enhanced macrophage-cardiomyocyte interaction improves normal AV nodal conduction, whereas reduced interaction leads to aberrant AV node conduction.

Monnerat et al demonstrated that, in diabetic mice, toll-like receptor 2 (TLR2) and NOD-like receptor protein 3 (NLRP3) inflammasome are activated in cardiac macrophages, resulting in the secretion of interleukin (IL)- $1 \beta .{ }^{59}$ IL-1 $\beta$-caused prolongation of the action potential duration induces a decrease in potassium current and an increase in calcium sparks in cardiomyocytes, which will cause arrhythmia propensity. Treatment with either an IL-1 receptor antagonist or inhibition of the NLRP3 inflammasome rescued the phenotype.

Cardiac macrophages also offer clues regarding the development of HFpEF. Hulsmans et al found that both in aged mice and hypertensive mice, cardiac macrophages produced IL-10, activated fibroblasts, and stimulated collagen deposition, leading to impaired myocardial relaxation and increased myocardial stiffness. Deletion of IL-10 in macrophages improved diastolic function. ${ }^{60}$

\section{Conclusions}

Elucidation of the novel roles of cardiac macrophages has opened new avenues for possible therapeutic interventions. Targeting macrophage function would be a more effective means by which to tackle arrhythmias and diastolic dysfunction than would targeting cardiomyocytes or fibroblasts. Therefore, as a next step, we need to know whether macrophage dysfunction leads to AV block, arrhythmia propensity in diabetes patients, and diastolic dysfunction in humans. If macrophage function is linked to cardiac function in humans, reprogramming macrophages in situ with antibodies, such as CSF-1R, CD68, or scavenger receptors, could be a viable form of immunotherapy.

\section{Disclosures}

The authors declare no conflicts of interest.

\section{References}

1. Schocken DD, Benjamin EJ, Fonarow GC, Krumholz HM, Levy D, Mensah GA, et al. American Heart Association Council on Epidemiology and Prevention, American Heart Association Council on Clinical Cardiology, American Heart Association Council on Cardiovascular Nursing, American Heart Association Council on High Blood Pressure Research, Quality of Care and Outcomes Research Interdisciplinary Working Group, Functional Genomics and Translational Biology Interdisciplinary Working Group. Prevention of heart failure: A scientific statement from the American Heart Association Councils on Epidemiology and Prevention, Clinical Cardiology, Cardiovascular Nursing, and High Blood Pressure Research; Quality of Care and Outcomes Research Interdisciplinary Working Group; and Functional Genomics and Translational Biology Interdisciplinary Working Group. Circulation 2008; 117: 2544-2565.

2. van Riet EE, Hoes AW, Wagenaar KP, Limburg A, Landman MA, Rutten FH. Epidemiology of heart failure: The prevalence of heart failure and ventricular dysfunction in older adults over time. A systematic review. Eur J Heart Fail 2016; 18: 242-252.

3. McMurray JJ, Adamopoulos S, Anker SD, Auricchio A, Bohm M, Dickstein K, et al. ESC guidelines for the diagnosis and treatment of acute and chronic heart failure 2012: The Task Force for the Diagnosis and Treatment of Acute and Chronic Heart Failure 2012 of the European Society of Cardiology. Developed in collaboration with the Heart Failure Association (HFA) of the ESC. Eur Heart J 2012; 33: 1787-1847.

4. Konishi M, Ishida J, Springer J, von Haehling S, Akashi YJ, Shimokawa $\mathrm{H}$, et al. Heart failure epidemiology and novel treatments in Japan: Facts and numbers. ESC Heart Fail 2016; 3: $145-151$.
5. Heidenreich PA, Albert NM, Allen LA, Bluemke DA, Butler J, Fonarow GC, et al. Forecasting the impact of heart failure in the United States: A policy statement from the American Heart Association. Circ Heart Fail 2013; 6: 606-619.

6. Melenovsky V, Hwang SJ, Lin G, Redfield MM, Borlaug BA. Right heart dysfunction in heart failure with preserved ejection fraction. Eur Heart J 2014; 35: 3452-3462.

7. Mohammed SF, Hussain I, AbouEzzeddine OF, Takahama $\mathrm{H}$, Kwon SH, Forfia P, et al. Right ventricular function in heart failure with preserved ejection fraction: A community-based study. Circulation 2014; 130: 2310-2320.

8. Vaduganathan M, Patel RB, Michel A, Shah SJ, Senni M, Gheorghiade M, et al. Mode of death in heart failure with preserved ejection fraction. J Am Coll Cardiol 2017; 69: 556-569.

9. Schinkel AF, Elhendy A, van Domburg RT, Biagini E, Rizzello $\mathrm{V}$, Veltman CE, et al. Prognostic significance of QRS duration in patients with suspected coronary artery disease referred for noninvasive evaluation of myocardial ischemia. Am J Cardiol 2009; 104: 1490-1493.

10. Elhendy A, Hammill SC, Mahoney DW, Pellikka PA. Relation of QRS duration on the surface 12-lead electrocardiogram with mortality in patients with known or suspected coronary artery disease. Am J Cardiol 2005; 96: 1082-1088.

11. Iuliano S, Fisher SG, Karasik PE, Fletcher RD, Singh SN. QRS duration and mortality in patients with congestive heart failure. Am Heart J 2002; 143: 1085-1091.

12. Kumar NM, Gilula NB. The gap junction communication channel. Cell 1996; 84: 381-388.

13. Alexander DB, Goldberg GS. Transfer of biologically important molecules between cells through gap junction channels. Curr Med Chem 2003; 10: 2045-2058.

14. Sohl G, Willecke K. Gap junctions and the connexin protein family. Cardiovasc Res 2004; 62: 228-232.

15. Sohl G, Willecke K. An update on connexin genes and their nomenclature in mouse and man. Cell Commun Adhes 2003; 10: $173-180$.

16. Joyner RW, van Capelle FJ. Propagation through electrically coupled cells: How a small SA node drives a large atrium. Biophys J 1986; 50: 1157-1164.

17. Joyner RW, Wang YG, Wilders R, Golod DA, Wagner MB, Kumar R, et al. A spontaneously active focus drives a model atrial sheet more easily than a model ventricular sheet. Am J Physiol Heart Circ Physiol 2000; 279: H752-H763.

18. Lambiase PD, Tinker A. Connexins in the heart. Cell Tissue Res 2015; 360: 675-684.

19. Coppen SR, Dupont E, Rothery S, Severs NJ. Connexin45 expression is preferentially associated with the ventricular conduction system in mouse and rat heart. Circ Res 1998; 82: $232-243$.

20. Coppen SR, Kodama I, Boyett MR, Dobrzynski H, Takagishi $\mathrm{Y}$, Honjo H, et al. Connexin45, a major connexin of the rabbit sinoatrial node, is co-expressed with connexin 43 in a restricted zone at the nodal-crista terminalis border. J Histochem Cytochem 1999; 47: 907-918.

21. Coppen SR, Severs NJ, Gourdie RG. Connexin45 (alpha 6) expression delineates an extended conduction system in the embryonic and mature rodent heart. Dev Genet 1999; 24: 82-90.

22. Kreuzberg MM, Schrickel JW, Ghanem A, Kim JS, Degen J, Janssen-Bienhold U, et al. Connexin 30.2 containing gap junction channels decelerate impulse propagation through the atrioventricular node. Proc Natl Acad Sci USA 2006; 103: 5959-5964.

23. Kreuzberg MM, Liebermann M, Segschneider S, Dobrowolski R, Dobrzynski H, Kaba R, et al. Human connexin31.9, unlike its orthologous protein connexin 30.2 in the mouse, is not detectable in the human cardiac conduction system. J Mol Cell Cardiol 2009; 46: 553-559.

24. Kreuzberg MM, Sohl G, Kim JS, Verselis VK, Willecke K, Bukauskas FF. Functional properties of mouse connexin 30.2 expressed in the conduction system of the heart. Circ Res 2005; 96: $1169-1177$.

25. Francis D, Stergiopoulos K, Ek-Vitorin JF, Cao FL, Taffet SM, Delmar M. Connexin diversity and gap junction regulation by pHi. Dev Genet 1999; 24: 123-136.

26. De Mello WC. Modulation of junctional permeability. Fed Proc 1984; 43: 2692-2696.

27. Spray DC, White RL, de Carvalho AC, Harris AL, Bennett MV. Gating of gap junction channels. Biophys $J$ 1984; 45: 219-230.

28. Arellano RO, Rivera A, Ramon F. Protein phosphorylation and hydrogen ions modulate calcium-induced closure of gap junction channels. Biophys J 1990; 57: 363-367. 
29. Massey KD, Minnich BN, Burt JM. Arachidonic acid and lipoxygenase metabolites uncouple neonatal rat cardiac myocyte pairs. Am J Physiol 1992; 263: C494-C501.

30. Wu J, McHowat J, Saffitz JE, Yamada KA, Corr PB. Inhibition of gap junctional conductance by long-chain acylcarnitines and their preferential accumulation in junctional sarcolemma during hypoxia. Circ Res 1993; 72: 879-889.

31. van Veen AA, van Rijen HV, Opthof T. Cardiac gap junction channels: Modulation of expression and channel properties. Cardiovasc Res 2001; 51: 217-229.

32. Shaw RM, Fay AJ, Puthenveedu MA, von Zastrow M, Jan YN, Jan LY. Microtubule plus-end-tracking proteins target gap junctions directly from the cell interior to adherens junctions. Cell 2007; 128: 547-560.

33. Beardslee MA, Laing JG, Beyer EC, Saffitz JE. Rapid turnover of connexin43 in the adult rat heart. Circ Res 1998; 83: 629-635.

34. Dunn CA, Lampe PD. Injury-triggered Akt phosphorylation of Cx43: A ZO-1-driven molecular switch that regulates gap junction size. J Cell Sci 2014; 127: 455-464.

35. Lampe PD, Lau AF. The effects of connexin phosphorylation on gap junctional communication. Int J Biochem Cell Biol 2004; 36: $1171-1186$.

36. Popolo A, Morello S, Sorrentino R, Pinto A. Antiadrenergic effect of adenosine involves connexin 43 turn-over in $\mathrm{H} 9 \mathrm{c} 2$ cells. Eur J Pharmacol 2013; 715: 56-61.

37. Takens-Kwak BR, Jongsma HJ. Cardiac gap junctions: Three distinct single channel conductances and their modulation by phosphorylating treatments. Pflugers Arch 1992; 422: 198-200.

38. Axelsen LN, Calloe K, Holstein-Rathlou NH, Nielsen MS. Managing the complexity of communication: Regulation of gap junctions by post-translational modification. Front Pharmacol 2013; 4: 130.

39. Solan JL, Lampe PD. Specific Cx43 phosphorylation events regulate gap junction turnover in vivo. FEBS Lett 2014; 588: $1423-1429$.

40. TenBroek EM, Lampe PD, Solan JL, Reynhout JK, Johnson RG. Ser364 of connexin 43 and the upregulation of gap junction assembly by cAMP. J Cell Biol 2001; 155: 1307-1318.

41. Lampe PD, TenBroek EM, Burt JM, Kurata WE, Johnson RG, Lau AF. Phosphorylation of connexin 43 on serine 368 by protein kinase $\mathrm{C}$ regulates gap junctional communication. $J$ Cell Biol 2000; 149: 1503-1512.

42. Lampe PD, Cooper CD, King TJ, Burt JM. Analysis of Connexin 43 phosphorylated at S325, S328 and S330 in normoxic and ischemic heart. J Cell Sci 2006; 119: 3435-3442.

43. Bao X, Reuss L, Altenberg GA. Regulation of purified and reconstituted connexin 43 hemichannels by protein kinase C-mediated phosphorylation of Serine 368. J Biol Chem 2004; 279: $20058-$ 20066.

44. Morel S, Frias MA, Rosker C, James RW, Rohr S, Kwak BR. The natural cardioprotective particle HDL modulates connexin 43 gap junction channels. Cardiovasc Res 2012; 93: 41-49.

45. Smyth JW, Zhang SS, Sanchez JM, Lamouille S, Vogan JM, Hesketh GG, et al. A 14-3-3 mode-1 binding motif initiates gap junction internalization during acute cardiac ischemia. Traffic 2014; 15: 684-699.

46. Duffy HS, Ashton AW, O'Donnell P, Coombs W, Taffet SM, Delmar M, et al. Regulation of connexin 43 protein complexes by intracellular acidification. Circ Res 2004; 94: 215-222.

47. Kieken F, Mutsaers N, Dolmatova E, Virgil K, Wit AL, Kellezi A, et al. Structural and molecular mechanisms of gap junction remodeling in epicardial border zone myocytes following myocardial infarction. Circ Res 2009; 104: 1103-1112.

48. Colussi C, Rosati J, Straino S, Spallotta F, Berni R, Stilli D, et al Nepsilon-lysine acetylation determines dissociation from GAP junctions and lateralization of connexin 43 in normal and dystrophic heart. Proc Natl Acad Sci USA 2011; 108: 2795-2800.

49. Xue J, Yan X, Yang Y, Chen M, Wu L, Gou Z, et al. Connexin 43 dephosphorylation contributes to arrhythmias and cardiomyocyte apoptosis in ischemia/reperfusion hearts. Basic Res Cardiol 2019; 114: 40 .

50. Kim E, Fishman GI. Designer gap junctions that prevent cardiac arrhythmias. Trends Cardiovasc Med 2013; 23: 33-38.

51. Ginhoux F, Jung S. Monocytes and macrophages: Developmental pathways and tissue homeostasis. Nat Rev Immunol 2014; 14: $392-404$.

52. Nguyen KD, Qiu Y, Cui X, Goh YP, Mwangi J, David T, et al. Alternatively activated macrophages produce catecholamines to sustain adaptive thermogenesis. Nature 2011; 480: 104-108.

53. Theurl I, Hilgendorf I, Nairz M, Tymoszuk P, Haschka D, Asshoff $\mathrm{M}$, et al. On-demand erythrocyte disposal and iron recycling requires transient macrophages in the liver. Nat Med 2016; 22: 945-951.

54. Paolicelli RC, Bolasco G, Pagani F, Maggi L, Scianni M, Panzanelli $\mathrm{P}$, et al. Synaptic pruning by microglia is necessary for normal brain development. Science 2011; 333: 1456-1458.

55. Davis MJ, Tsang TM, Qiu Y, Dayrit JK, Freij JB, Huffnagle GB, et al. Macrophage M1/M2 polarization dynamically adapts to changes in cytokine microenvironments in Cryptococcus neoformans infection. MBio 2013; 4: e00264-13.

56. Pinto AR, Paolicelli R, Salimova E, Gospocic J, Slonimsky E, Bilbao-Cortes D, et al. An abundant tissue macrophage population in the adult murine heart with a distinct alternatively-activated macrophage profile. PloS One 2012; 7: e36814.

57. Bajpai G, Bredemeyer A, Li W, Zaitsev K, Koenig AL, Lokshina I, et al. Tissue resident CCR2- and CCR2+ cardiac macrophages differentially orchestrate monocyte recruitment and fate specification following myocardial injury. Circ Res 2019; 124: 263-278.

58. Hulsmans M, Clauss S, Xiao L, Aguirre AD, King KR, Hanley A, et al. Macrophages facilitate electrical conduction in the heart. Cell 2017; 169: 510-522.e20.

59. Monnerat G, Alarcon ML, Vasconcellos LR, Hochman-Mendez C, Brasil G, Bassani RA, et al. Macrophage-dependent IL-1beta production induces cardiac arrhythmias in diabetic mice. Nat Commun 2016; 7: 13344.

60. Hulsmans M, Sager HB, Roh JD, Valero-Munoz M, Houstis $\mathrm{NE}$, Iwamoto $\mathrm{Y}$, et al. Cardiac macrophages promote diastolic dysfunction. $J$ Exp Med 2018; 215: 423-440. 